\title{
The Use of Thanking Expressions and Their Intensifiers from Early Modern to Present Day English
}

\author{
Basma Mahmoud Mohamed El-Mahallawi \\ Assistant lecturer, Department of English \\ Faculty of Al-Alsun, Minia University
}

\begin{abstract}
The current research paper carries out a diachronic examination of the illocutionary force indicating devices (i.e. formulaic, routinized expressions) of thanking and their intensifiers across the history of Modern English. The findings of the study have revealed that the routinized expressions of thanking predominantly used in Early Modern, Late Modern, and Present Day English are the IFIDs thank (v.) and thanks (n.). However, starting from the Late Modern period, the speech act of thanking has gradually developed from being explicitly to being implicitly performative, which indicates an increasing trend towards routinization and a partial loss of its illocutionary force due to such routinization. Furthermore, the patterns of use of the intensifiers of thanking across the history of Modern English have revealed a shift from a culture which stresses the differences between social classes in the $16^{\text {th }}$ and $17^{\text {th }}$ centuries to one which emphasizes the importance of democracy and equality starting from the late $18^{\text {th }}$ century onwards. For instance, titles of respect have gradually developed from chiefly being markers of aristocracy and authority into mainly being address forms which show respect to the addressees regardless of their social standing, and intensifying adverbials which involve self-deprecation and operate in accordance with Leech's (1983) Maxim of Modesty (e.g. humbly) have gradually fallen out of use in LME and disappeared altogether in PDE.
\end{abstract}

\section{Introduction}

A word of thanks has the power to preserve the social harmony between people. It is an effective tool through which speakers seek to restore the equilibrium with the addressees by expressing their gratitude for their acts of benefit. Therefore, failing to thank someone efficiently may have detrimental consequences, because it may lead that person to feel undermined or to doubt the worth of his or her own deed. Thus, it makes sense to assume that the speech act of thanking has been an important part of linguistic interaction along the history of the English language. It is a culturally sensitive speech act insofar as it reflects people's perceptions of politeness and socially acceptable behavior within a certain era. As such, studying the speech act of thanking across the history of Modern English can give insights into the social and cultural conditions of different Modern English periods and reflect the general notions of politeness therein.

As a technical term, the speech act of thanking can be defined as a kind of illocutionary act performed by the speaker based on an act done by the hearer in the past, which has some benefits for the speaker of which he or she is aware (Eisenstein and Bodman, 1986, p. 167). Due to being expressive, the speech act of thanking is characterize by each of the following features: (1) factivity, i.e. the truth of the state 
of affairs is presupposed by the speaker, (2) expressing a psychological state, and (3) expressing some property ascribed to the speaker or the hearer (Aijmer, 1996, p. 34). The felicity conditions of the speech act of thanking can be formulated as follows:

Propositional content
Preparatory condition
Sincerity condition
Essential condition

Past act A done by $\mathrm{H}$.

A benefits $\mathrm{S}$ and $\mathrm{S}$ believes $\mathrm{A}$ benefits $\mathrm{S}$.

$\mathrm{S}$ feels grateful or appreciative for A.

Counts as an expression of gratitude or appreciation.

67)

The current research paper carries out a diachronic examination of the illocutionary force indicating devices (i.e. the formulaic, routinized expressions) used by speakers to perform the speech act of thanking across the history of Modern English. The paper also examines the lexemes used by speakers to intensify the expressions of thanking in order to stress their genuine intentions and accentuate the sincerity of the speech act.

In this study, Modern English is divided into three periods: Early Modern English (1500-1700), Late Modern English (1700- 1900), and Present-Day English (1900-present). Early Modern English (henceforth EME) dates back to the beginning of the reign of the Tudor family in England. A number of events account for the transition from Late Middle English to Early Modern English, most important of which are the invention of printing in 1476, which has contributed greatly to the standardization of language and the promotion of literacy, and the Great Vowel Shift which gave way to the development of the English phonological system. On the other hand, the beginning of the Late Modern English period (henceforth LME) is usually associated with that of the Age of Enlightenment, which has witnessed great scientific discoveries and the triumph of knowledge over superstition. Scientific progress in the Age of Enlightenment has influenced language in more than one way. For instance, lexical innovations became necessary in order to cope with the new inventions of the age, and dialect contact became common due to the breakthrough in transportation which increased the mobility of people. Lastly, the Present-Day English period (henceforth PDE) starts around the early twentieth century. This period involves the development of English into the closest form spoken by people nowadays. It is in this period, however, that the gap between different national varieties of English, e.g. British, American, Australian, etc, began to reach its peak.

\section{Description of data}

The present study relies on plays for the diachronic investigation of the IFIDs of thanking across the history of Modern English. Even though there are some reservations about how far dramatic texts can be taken to be representative of spoken interaction, plays can be thought of as "fictional accounts [which] give us an approximation of the real spoken language in different historical and sociocultural contexts" (Jucker, 2006, p. 326).

Thus, data for this study are drawn from nine plays, each three of which represent a stage in the development of Modern English. The first three plays, Dr. 
Faustus (1604) by Christopher Marlowe, The Alchemist (1610) by Ben Jonson, and Othello (1622) by Shakespeare, were written during the period of Early Modern English, which extended from 1500 to 1700. The following three plays, The Way of the World (1700) by William Congreve, The School for Scandal (1777) by Richard Brinsley Sheridan, and The Importance of Being Earnest (1898) by Oscar Wilde, are representative of Late Modern English (1700-1900), the period which ensued Early Modern English and represented the transitional phase to Present-Day English. The last three plays represent the last stage in Modern English, i.e. Present Day English (from 1900 to present), which involves the development of English into the form spoken by people nowadays; these plays are Pygmalion (1912) by George Bernard Shaw, Look Back in Anger (1956) by John Osborne, and Jerusalem (2009) by Jez Butterworth.

Furthermore, the results of the quantitative analysis of the IFIDs in the plays are compared to those of the same IFIDs in three large electronic corpora, namely The Lampeter Corpus of Early Modern English Tracts (Schmied, Claridge, \& Siemund, 1999), The Corpus of Late Modern English Texts (Hendrik, Flach, Tyrkko, \& Diller, 2015), and the British National Corpus (2007) which represent Early Modern, Late Modern, and Present Day English respectively. By comparing the results of the corpus of the nine plays used in this study on the one hand and those of the three large corpora previously mentioned on the other, the researcher aims to validate and supplement the results of the study, especially when the count of some linguistic features is found to be very low, if non-existent, as will be shown later. The quantitative analysis of some of the thanking IFIDs in the Lampter Corpus of Early Modern English Tracts and Corpus of Late Modern English Texts is done using a concordance program called AntConc (Anthony, 2014), while that of the British National corpus is done using the websites http://corpus.byu.edu/bnc/ and http://bncweb.lancs.ac.uk/ which allow the online investigation of the corpus free of charge.

\section{Illocutionary force indicating devices}

The corpus of the study shows minor changes with regard to speakers' use of the IFIDs of thanking along the history of Modern English. As illustrated by Table 1, the most popular IFID of thanking throughout the corpus of the three periods of Modern English is the verb thank, followed by the noun thanks ${ }^{1}$.

\begin{tabular}{|c|c|c|c|}
\cline { 2 - 4 } \multicolumn{1}{c|}{} & IFID & $\begin{array}{c}\text { No. of } \\
\text { occurrences }\end{array}$ & $\begin{array}{c}\text { Frequency of } \\
\text { occurrence }\end{array}$ \\
\hline \multirow{2}{*}{ EME } & thank $(v)$. & 15 & $62.5 \%$ \\
& thanks $(n)$. & 7 & $29.2 \%$ \\
& bound & 2 & $8.3 \%$ \\
\hline
\end{tabular}




\begin{tabular}{|c|c|c|c|}
\hline \multirow{3}{*}{ LME } & thank (v.) & 29 & $74.4 \%$ \\
& thanks (n.) & 3 & $7.7 \%$ \\
& obliged & 3 & $7.7 \%$ \\
& owe & 3 & $7.7 \%$ \\
& grateful & 1 & $2.5 \%$ \\
\hline \multirow{7}{*}{ PDE } & thank $(v)$. & 38 & $73 \%$ \\
& thanks $(n)$. & 13 & $25 \%$ \\
& grateful & 1 & $2 \%$ \\
\hline
\end{tabular}

Table 1. Thanking IFIDs and their frequency of occurrence in EME, LME, and PDE

In the EME and LME corpus, the verb thank is usually preceded by the first person pronoun $I$ and followed by either the second person, as in 1a and 1b, or (less commonly) the third person in order to show deference and respect as in 1c:

(1) a. I thank you, valiant Cassio. (Othello, p. 38)

b. I am vastly glad to see you, I thank you for this call. (The School for Scandal, p. 58)

c. I thank his worship. (The Alchemist, p. 123)

However, towards the end of LME and throughout the PDE corpus, the first-person subject of the verb thank is usually omitted, as in:

(1) d. Thank you, Algernon. It is very thoughtful of you. (The Importance of Being Earnest, p. 61)

e. Oh, you are real good. Thank you, Captain. (Pygmalion, p. 32)

f. Thank you. Thank you, Tanya. Thank you to all. (Jerusalem, p. 51)

As such, starting from LME, the speech act of thanking has gradually developed from an explicit performative formula (first person singular $I+$ performative verb thank + second person subject you) into the routinized, short structure thank you, which is implicitly performative. This shift from explicitly to implicitly performative suggests that the speech act of thanking has become more routinized and that its illocutionary force has started to lose some of its strength over the course of time ${ }^{2}$. The routinization of the speech of thanking that gradually increased from the late $18^{\text {th }}$ century onwards can be explained in terms of the tempo of life of the British society, which became faster around the LME period due to the Industrial Revolution and was accelerated even more in the twentieth and twenty-first centuries because of the breakthroughs in communication, transportation, and technology.

Unlike the verb thank, which has begun to appear in the popular elliptical structure thank you only towards the end of LME, the noun thanks mostly occurs in sentences where the subject and verb are omitted altogether even in as early as EME and throughout LME and PDE:

(2) a. Great thanks, mighty Lucifer!

This will I keep as chary as my life (Dr. Faustus, p. 39)

b. Thanks, courteous Ananias. (The Alchemist, p. 191) 
c. Thanks, mamma, I'm quite comfortable where I am. (The

Importance of Being Earnest, p. 59)

d. Thanks, Wesley. And Sue. I'm touched. (Jerusalem, p. 54)

There are only two instances in which thanks is used in non-elliptical structures in the EME and LME corpus, where the IFID collocates with the verbs return and greet respectively:

(2) e. I greet thy love,

Not with vain thanks, but with acceptance bounteous [...] (Othello, p. 92)

f. Hold, Lady Sneerwell; before you go, give me leave to return you thanks, for the trouble you and this gentleman took, in writing letters in my name to Charles and answering them yourself. (The School for Scandal, p. 84)

It should be noted, however, that the use of the IFID thanks in non-elliptical structures seems to be associated with the level of formality of the talk exchange, especially in the LME and PDE periods ${ }^{3}$. That is to say, when thanks is used in complete, non-elliptical structures, the style of the talk exchange is usually very formal and polite.

One reason why the IFIDs thank (v.) and thanks (n.) are the most popular throughout the corpus of the three periods is that they are compatible with the spirit of EME, LME, and PDE societies. They can be used to express the speaker's gratitude without contradicting the emphasis on respectability and deference which dominated the Elizabethan society or the rules of etiquette that pervaded the conservative Victorian society during the nineteenth century. The IFIDs also suit the non-imposition culture of the twentieth and twenty-first centuries, where egalitarian and liberal values became part and parcel of the life of the English society.

Other less commonly used IFIDs of thanking are those which express gratitude (such as grateful) and indebtedness (such as bound, obliged, and owe). IFIDs which express gratitude are rarely found in the LME and PDE corpus, and are not found at all in the EME corpus ${ }^{4}$. In the following examples, the IFID grateful makes the speech act of thanking seem more serious and sincere than it would be if the IFIDs thank or thanks were used:

(3) a. I am your very much obliged and, and most grateful humble servant. (The School for Scandal, p. 53)

b. We were very grateful that you did. (Look back in Anger, p. 63)

In the two examples above, the act of benefit for which the addressee is being thanked is of great importance to the speaker, so a more sincere form of thanking is required. In 3a, the speaker thanks the addressee for telling him that he will lend him the money he needs as soon as possible. In 3b, Alison's parents thank Helena for writing to them about their daughter's miserable life with her husband so that they can come and relieve her suffering. Perhaps the reason why speech acts of thanking where expressions of gratitude like grateful and gratitude are used seem more sincere is that the overwhelming use of the IFIDs thank (v.) and thanks (n.) makes the speech act of thanking seem more formulaic and routinized and consequently 
less sincere than other speech acts of thanking where less commonly used IFIDs are found.

Expressions of indebtedness are rarely found in the EME and LME corpus and are not found at all in the PDE corpus. Examples from the EME and LME corpus are:

(4) a. I am much bound to you. (Othello, p. 68)

b. I am obliged to you that you would make me your proxy in this affair, but I have business of my own. (The Way of the World, p. 51)

c. [...] I owe much to you. (The School for Scandal, p. 86)

Perhaps speakers of Modern English generally avoid IFIDs of thanking which express indebtedness because they involve a high degree of imposition on the speaker, who returns the addressee's favor by expressing his or her indebtedness to the latter ${ }^{5}$. Expressions of indebtedness are also specifically hazardous to the democratic, egalitarian values of the twentieth and twenty-first century life, which advocate one's own personal freedom and right not to be imposed on.

\section{Intensifiers of illocutionary force indicating devices}

Because there are many occasions on which the speech act of thanking is ritualized to the extent that its sincerity can be questionable, intensification plays a very important role in manifesting speakers' genuine intentions and creating more polite gratitude expressions. The current section of the study will focus on the internal intensifiers of thanking, i.e. intensifiers which occur in the same sentence where the IFIDs are located.

Based on the examination of the corpus, the study has categorized the intensifiers of the IFIDs of thanking into (1) titles of respect, e.g. "Thank you, sir", (2) terms of endearment, e.g. "Thanks, babe", (3) intensifying adverbials, e.g. "Thank you very much", (4) emphatic do, e.g. "I do feel grateful for your help", and (5) emotional expressions, e.g. "Ohhh, thank you."

Upon the examination of the corpus of the study, it has been found that the most commonly used intensifiers of thanking throughout the three periods of Modern English are titles of respect, terms of endearment and intensifying adverbials which are commonly found in varying frequencies in EME, LME, and PDE. On the other hand, emphatic $d o$ and emotional expressions are rarely used in the entire corpus of the study, where the former is only found in the EME corpus and the latter only in the PDE corpus. Below is a detailed discussion of every intensifier and the implications of its use in relation to the notions of politeness as well as the cultural and social conditions which dominated each period along the history of Modern English.

\begin{tabular}{|c|c|c|c|}
\hline IFID intensifier & EME & LME & PDE \\
\hline 1. Titles of respect & $58.33 \%$ & $31.25 \%$ & $37.5 \%$ \\
\hline
\end{tabular}




\begin{tabular}{|c|c|c|c|}
\hline 2. Terms of endearment & $8.33 \%$ & $50 \%$ & $20.83 \%$ \\
\hline 3. Intensifying adverbials & $29.17 \%$ & $18.75 \%$ & $25 \%$ \\
\hline 4. Emphatic do & $4.17 \%$ & --- & --- \\
\hline 5. Emotional expressions & --- & --- & $16.67 \%$ \\
\hline
\end{tabular}

Table 2. The frequency and distribution of the intensifiers of thanking in EME,

LME, and PDE

\section{a. Titles of respect}

Titles of respect are the most commonly used intensifiers of thanking in EME, because they help show deference to the addressee by acknowledging their high social standing or authority, thus reinforcing the Elizabethan idea of fixed social hierarchy. Examples are:

(5) a. Lodovico: Madam, good night; I humbly thank your Desdemona: ladyship.

Your honour is most welcome. (Othello, p. 134)

b. Faustus: I humbly thank your grace.

(Dr. Faustus, p. 58)

In 5a, Lodovico thanks Desdemona for her hospitality; the title of respect your ladyship designates Desdemona's high social standing. In 5b, Faustus gives thanks to the Duchess for her courtesy; the title of respect your grace signals both the noble origin and authoritative of the addressee. In both examples, using titles of respect brings no surprise because the relationship between the interlocutors is very formal.

In the LME and PDE corpus, titles of respect are still commonly used by speakers to intensify the speech act of thanking by showing deference to the addressee to whom the speaker is being grateful. Their popularity in the LME and PDE periods can be ascribed to the fact that they are compatible with the culture of non-imposition which has emerged in the eighteenth century and thrived in the nineteenth, twentieth and twenty-first centuries.

It should be noted, however, that titles of respect have undergone an important development starting from the LME period. Whereas titles of respect in EME have aristocratic connotations and are mainly used to designate certain social ranks or authority, in LME they are used either to signal the social rank of the addressee or to show deference and respect regardless of the social status of the addressee. Examples are:

$$
\begin{aligned}
& \text { c. Sir Oliver: } \\
& \text { Sir Peter: }
\end{aligned}
$$

d. Algernon:

Lane:
Ah, my dear friend, I rejoice to see you! [...] Thank you, thank you, Sir Peter - and I am glad to find you so well, believe me. (The School for Scandal, p. 30)

Very natural, I am sure. That will do, Lane, thank you.

Thank you, sir.

In 5c, the title Sir has aristocratic connotations, whereas in $5 \mathrm{~d}$ it is mainly used to designate respect without making reference to the social rank of the speaker. Example 5c is particularly interesting because the title of respect is used by the speaker to address someone who is socially equal to him and who also happens to be his friend. In this case, the address form Sir is mainly used to show that the speaker 
takes pride in the social class to which he and the addressee belong, i.e. it functions as a marker of in-group identity.

In the PDE corpus, titles of respect which intensify the speech act of thanking are mostly devoid of any aristocratic or authority-related connotations, as in:

(5) e. Mrs. Pearce: Thank you, sir. That's all. (Pygmalion, p. 45)

f. Doolittle: [To Pickering] Thank you, Governor. Good morning. (Pygmalion, p. 55)

In 5 e, the title sir, which was originally used to designate a high social rank (and still does within some contexts in the United Kingdom to this day), has developed another function where it can be used to show respect regardless of the social status of the hearer. In 5f, the title of respect Governor has also undergone a semantic change in this context, where it does not refer to someone who rules or governs (authoritative position), but is rather used as a polite address form for a man.

Therefore, titles of respect have undergone an important change in that they have gradually developed from chiefly being markers of aristocracy, high social rank and authority into mainly being address forms which show respect to the speaker regardless of his or her social standing. This shift in function can be explained in terms of the social changes that have taken place in Britain around the late $18^{\text {th }}$ century. In the sixteenth and seventeenth centuries, Elizabethan and Restoration societies were to a great extent controlled by a fixed social hierarchy, where people mainly inherited aristocratic titles from their predecessors. Around the late eighteenth century, the situation has changed. The Industrial Revolution resulted in social mobility, where common, non-aristocratic people acquired wealth through hard work. Further, the spread of democratic values and increased secularization helped people break free from the tyranny of the fixed social order of the Elizabethan society. All these changes have made aristocratic titles of less significance in LME and PDE than they were in EME.

\section{b. Terms of endearment}

The use of terms of endearment as intensifiers of thanking is not very common in the EME corpus ${ }^{6}$; only two instances have been found:

(6) a. Thanks, good Master Doctor: and, for I see your courteous intent to pleasure me [...] (Faustus, p. 57)

b. Thanks, courteous Ananias. (The Alchemist, p. 191)

Unlike titles of respect, terms of endearment are oriented towards the addressee's positive face and act as indicators of the close relationship between the interlocutors (cf. Jautz, 2013). The reason why terms of endearment are so scarce in the EME corpus can be ascribed to the high respectability and rigid differences between social classes in the Elizabethan and Restoration periods. Under these conditions, the speech act of thanking might have been generally perceived at that time as an act of deference which should emphasize the addressee's social standing rather than highlight the friendly or intimate relationship between the speaker and the addressee.

Terms of endearment are more commonly used in the speech acts of thanking in the LME and PDE plays. The increasing popularity of the terms of endearment in these two periods could be attributed to the gradual decline in the importance of 
observing the rigid differences between social classes in the EME society and the rise of the egalitarian values in the LME and PDE societies. Examples of terms of endearment from the corpus of LME and PDE are:

(6) c. Foible:

Lady Wishfort: Ay, dear Foible; thank thee for that, dear Foible. (The Way of the World, p. 34)

d. Lady Bracknell: Won't you come and sit here, Gwendolen?

Gwendolen: Thanks, mamma, I'm quite comfortable where I am. (The Importance of Being Earnest, p.59)

e. Mrs. Higgins: Oh, quite nice. I shall always be delighted to see him.

Mrs. Eynsford: Thank you, dear. Good-bye. (Pygmalion, p. 91)

f. Alison:

Cliff:
Now try and look after them. I'll give them a real press later on.

Thank you, you beautiful, darling girl. (Look Back in Anger, p. 17)

Terms of endearment intensify the speech act of thanking by appealing to the intimate relationship between the speaker on the one hand and the addressee on the other. Even though they indicate intimacy, terms of endearment are usually (but not always) used among equals. In 6c, the term of endearment dear is used by Lady Wishfort to address her maid Foible, while, in $6 \mathrm{~d}$, e, and $\mathrm{f}$, the terms of endearment mamma, dear, and darling are used by speakers who belong to the same social class as the addressees. In $6 \mathrm{~d}$, the term of endearment mamma is used by Gwendolen to address her mother; in 6e, Mrs. Eynsford uses the term of endearment dear to thank her friend and hostess, Mrs. Higgins, for welcoming her at her home; and in 6f, Cliff uses the term of endearment darling while thanking Alison, his friend's wife, for ironing his clothes. In such instances, terms of endearment are aimed at the addressee's positive face by stressing the solidarity and friendliness between the speaker and the addressee.

\section{c. Intensifying adverbials}

The use of intensifying adverbials in the corpus of EME, LME, and PDE reveals a remarkable change with regard to the politeness practices and social conditions which pervaded each period in Modern English. In EME, the adverbial intensifiers of the speech act of thanking mainly operate in accordance with Leech's (1983) Maxim of Modesty which stipulated that in order to show politeness one should minimize praise and maximize dispraise of self. Thus, the most commonly used adverbial intensifier of thanking in the EME corpus is humbly, which co-occurs with the verb thank in complete, non-elliptical sentences, as in:

(7) a. Humbly I thank your grace. (Othello, p. 20)

b. I humbly thank you for't. (Othello, p. 67) 


\section{c. I humbly thank your grace. (Dr. Faustus, p. 58)}

Aside from humbly, there are two instances in the corpus where the adverbs much and forever are used as internal intensifiers of thanking. Even though these two adverbs involve no self-deprecation, they accompany the IFID bound which entails the speaker's indebtedness and subservience to the addressee:
(7)
d. I am much bound to you. (Othello, p. 68)
e. I am bound to thee for ever. (Othello, p. 80)

The use of intensifying adverbials which involve self-deprecation and humility in EME suggests that speakers of that period essentially thought that gratitude should be expressed in terms of the speaker's inferiority and subservience to the addressee. This could be linked to the social conditions that surrounded the Elizabethan age, which was marked by the huge gap between social classes as well as the Church's emphasis on the importance of obeying those who are of higher social standing (mainly the monarch, followed by the aristocracy). Under these conditions, showing deference and implying one's inferiority to the Other were essential manifestations of politeness.

In the LME and PDE corpus, these self-deprecating expressions have disappeared $^{7}$ and speakers have become increasingly inclined to use intensifying adverbials which are mostly neutral on the positive-negative politeness scale. Examples are:

(8) a. I thank you heartily, heartily. (The Way of the World, p. 8)

b. Very well, madam, very well; I am much obliged to you for the Hint. (p. 21)

c. Thank you kindly, lady. (Pygmalion, p. 11)

d. Yes. Thanks awfully. Good-bye. (Pygmalion, p. 76)

e. We were very grateful that you did. (Look Back in Anger, p. 63)

f. Thanks very much. Cheers. Whatever. (Jerusalem, p. 53)

The shift from intensifying adverbials which imply self-deprecation to those which are mostly neutral on the positive-negative politeness scale implies a shift from a culture which celebrates the differences between social classes in the sixteenth and seventeenth centuries to one which emphasizes the importance of democracy and equality starting from the eighteenth century.

This shift towards egalitarianism is also mirrored in the fact that the most commonly used adverbial intensifier of thanking in PDE is very/very much $^{8}$. Indeed, the intensifying adverbs kindly and awfully are found only in the earliest play in the PDE corpus, i.e. Pygmalion. On the other hand, the only intensifying adverb used in the other two plays of the PDE corpus is very/very much, which is oriented towards neither the positive nor negative face of the speaker; instead, it serves to boost the act of thanking without referring to any of the interlocutors or the relationship between them. 


\section{d. Other less commonly used intensifiers}

The use of emphatic do as an internal intensifier of thanking is very rare in the corpus. There is only one example where emphatic $d o$ is used as an internal intensifier of thanking in the EME corpus:

(9) Sir, I do thank his worship. (The Alchemist, p. 150)

In the example above, the use of emphatic do helps intensify the speech act of thanking by placing more emphasis on the performative verb thank. Whereas titles of respect are oriented towards the addressee's negative face and terms of endearment towards his/her positive one, emphatic do is a neutral intensifier which helps stress the act of thanking and the speaker's gratitude while appealing to neither the addressee's negative nor positive face. It is worth noting that the use of emphatic $d o$ as an intensifier is detected neither in the LME nor PDE corpus because in EME emphatic do co-occurs with the verb thank in the complete, non-elliptical structure $I$ thank you, which is hardly used in the LME and PDE period ${ }^{9}$.

Emotional expressions as intensifiers of thanking are not commonly used in the corpus of the study ${ }^{10}$. Emotional expressions intensify the speech act of thanking by showing the speaker's reaction to the addressee's beneficial act; they emphasize the speaker's gratitude by showing his/her excitement and content for which the addressee takes credit. As an intensifying device, emotional expressions hardly qualify as negative or positive politeness markers; they are not directed towards the addressee's face but rather towards amplifying the act of thanking itself. Examples from the PDE plays in which emotional expressions are used to intensify the speech act of thanking include:

(10) a. The mother: [...] You can keep the change. The flower Oh, thank you, lady. (Pygmalion, p. 11) girl:

b. Helena: Here you are, Cliff. (Handing him the shirt.) Cliff: Oh, thanks, Helena, very much. That's decent of you. (Look Back in Anger, p. 79)

In 10a, the flower girl shows her gratitude to the mother when the latter asks her to keep the change to herself; the emotional expression $O h$ reveals a mixture of the flower girl's excitement, happiness, and gratitude. Similarly, in 10b, Cliff thanks Helena for pressing his shirt for him, where his sense of gratitude is further conveyed by the emotional expression $O h$. It is worth noting that the emotional expression $O h$ is used both between equals as in $10 \mathrm{~b}$ or non-equals as in 10a. The reason why emotional expressions are hardly used in the corpus of the study could be that they are features of spoken language, whereas the corpus of the study consists of plays which (despite being representative of spoken interactions) are in the written mode.

One final observation to be made about the internal intensification of thanking in Modern English is that speakers of EME intensify their expressions of gratitude the most, followed by those of LME, and finally PDE. Indeed, upon examining the corpus, it has been found that $71 \%$ of the IFIDs in EME are intensified as opposed to $41 \%$ in LME and $40 \%$ in PDE (see Graph 1). The gradual decrease in the 
frequency of intensification from EME to PDE can be ascribed to three reasons. First, as noted earlier, the tempo of life in the fifteenth and sixteenth centuries was relaxed, while starting from the eighteenth century the tempo of life was accelerated due to the Industrial Revolution and the ensuing breakthroughs in science and technology. As such, speakers in EME are more tempted to invest their time and effort in intensifying their expressions of thanking, while those of LME and PDE may feel urged to formulate short, routinized expressions of gratitude that are less time-consuming. Second, stressing the sincerity of the speech act of thanking is very important to the Elizabethan speakers of the EME period, which was characterized by heightened, if not exaggerated, forms of respect for the Other. On the other hand, starting from the eighteenth century onwards, the busy life of the urban British society has had its toll on social relationships, which have become of more superficial and transitory nature, thus making speakers of LME and PDE less obliged to manifest the sincerity of their speech act of thanking by means of intensification.

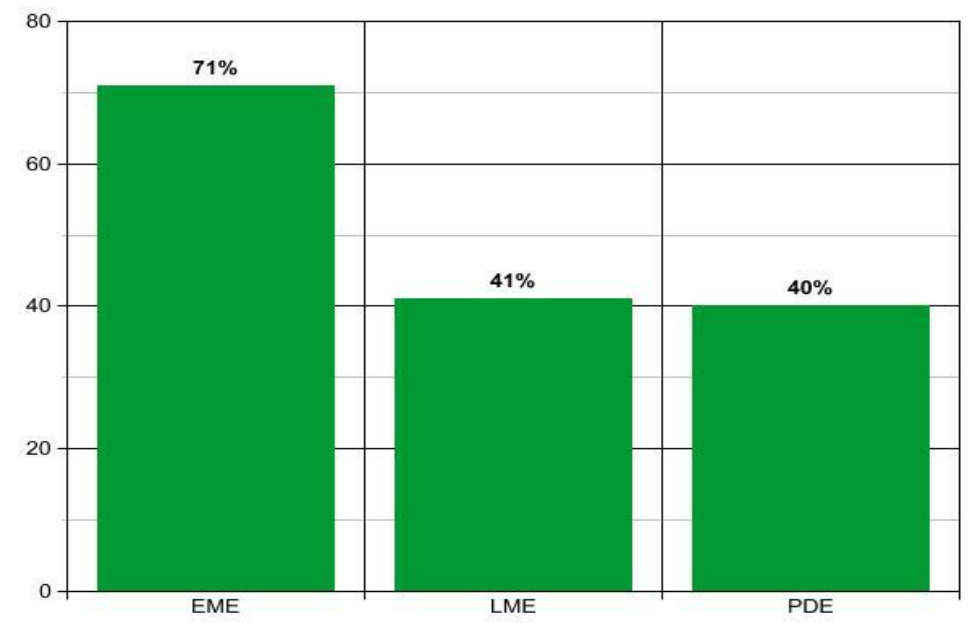

Graph 1 . Frequency of intensification in the EME, LME, and PDE corpus

\section{Conclusion}

As far as the use of the thanking IFIDs in EME, LME, and PDE is concerned, one can sum up the findings of the paper as follows. First, the speech act of thanking has undergone little development in terms of the routinized expressions most commonly used, because the IFIDs thank (v.) and thanks $(n$.$) are the most popular among$ speakers of EME, LME, and PDE altogether. Second, starting from the LME period, the speech act of thanking has gradually developed from being explicitly to being implicitly performative. This shift indicates an increasing trend towards routinization and a partial loss of its illocutionary force due to such routinization. Third, expressions of explicit gratitude (such as grateful) are generally less commonly used than the IFIDs thank and thanks, and for this reason they are usually associated with a lesser level of routinization and a higher level of sincerity. Fourth, expressions of indebtedness are generally disfavored by speakers of the three 
periods of Modern English due to the great risk they pose to the speaker's negative face.

As far as the internal intensifiers of thanking are concerned, the EME, LME, and PDE periods are similar in that the most commonly used intensifiers of thanking throughout the three periods are titles of respect, terms of endearment and intensifying adverbials. That being said, there are some changes with regard to the patterns of use of these intensifiers across the history of Modern English. First, titles of respect have gradually developed from chiefly being markers of aristocracy, high social rank and authority into mainly being address forms which show respect to the speaker regardless of his or her social standing. Second, terms of endearment are less commonly used in EME than they are in LME and PDE. Such can be ascribed to the high respectability and rigid differences between social classes in the Elizabethan and Restoration periods. Under these conditions, the speech act of thanking might have been generally perceived at that time as an act of deference which should emphasize the addressee's social standing rather than highlight the friendly or intimate relationship between the speaker and the addressee. Third, intensifiers which involve self-deprecation and operate in accordance with Leech's (1983) Maxim of Modesty, such as humbly, are hardly used in LME and PDE, where speakers have become increasingly inclined to use intensifying adverbials that are mostly neutral on the positive-negative politeness scale, such as very and so. All these changes in the use of lexical intensifiers mirror a shift from a culture which celebrates the differences between social classes in the sixteenth and seventeenth centuries to one which emphasizes the importance of democracy and equality starting from the late eighteenth century.

\section{References}

Aijmer, K. (1996). Conversational routines in English. London/New York: Longman.

Anthony, L. (2014). AntConc 3.4.4w [Computer software]. Tokyo: Waseda University. Retrieved from http://www.laurenceanthony.net/

Butterworth, J. (2009). Jerusalem. London: Nick Hern Books.

Congreve, W. (1767). The way of the world. London: J. \& R. Tonson. (Original work published 1700)

Eisenstein, M., \& Bodman, J. (1986). 'I very appreciate': Expressions of gratitude by native and non-native speakers of American English. Applied Linguistics, 7(2), 167-185. DOI: https://doi.org/10.1093/applin/7.2.167

Hendrik, S., Flach, S., Tyrkko, J, \& Diller, H. (2015). Corpus of Late Modern English texts (Version 3.1). Available from https://perswww.kuleuven.be/ u0044428/ 
Jautz, S. (2013). Thanking formulae in English: Explorations across varieties and genres (Vol. 230). Philadelphia: John Benjamins Publishing.

Jonson, B. (2004). The alchemist. In R. Shaughnessy (Ed.), Four renaissance comedies (pp. 105-230). New York: Palgrave Macmillan. (Original work published 1610)

Jucker, A. H. (2006). Historical pragmatics. In J. L. Mey (Ed.), Concise encyclopedia of pragmatics (pp. 325-328). Oxford: Elsevier.

Leech, G. (1983). Principles of pragmatics. London: Longman.

Marlowe, C. (2005). Dr. Faustus: Webster's thesaurus edition (P. M. Parker, Ed.). San Diego: Icon Classics. (Original work published 1604)

Osbourne, J. (2002). Look back in Anger (A. N. Jeffares, Ed.). Beirut: York Classics. (Original work published 1959)

Schmied,J., Claridge, C., \& Siemund, R. (1999). The Lampeter corpus of Early Modern English tracts. Retrieved from http://ota.ox.ac.uk/desc/2400

Searle, J. (1969). Speech acts. Cambridge: Cambridge University Press.

Shakespeare, W. (2005). Othello: Webster's thesaurus edition (P. M. Parker, Ed.). San Diego: Icon Classics. (Original work published 1622)

Shaw, G. B. (2005). Pygmalion: Webster's thesaurus edition (P. M. Parker, Ed.). San Diego: Icon Classics. (Original work published 1912)

Sheridan, R. B. (1820). The school for scandal. New York: Thomas Longworth. (Original work published 1777)

The British National Corpus (Version 3, BNC XML ed.). (2007). Distributed by Oxford University Computing Services on behalf of the BNC Consortium. http://www.natcorp.ox.ac.uk/

Wilde, O. (2004). The importance of being earnest (R. Jackson, Ed.). New York: Norton and Company Inc. (Original work published 1898) 


\section{Appendix}

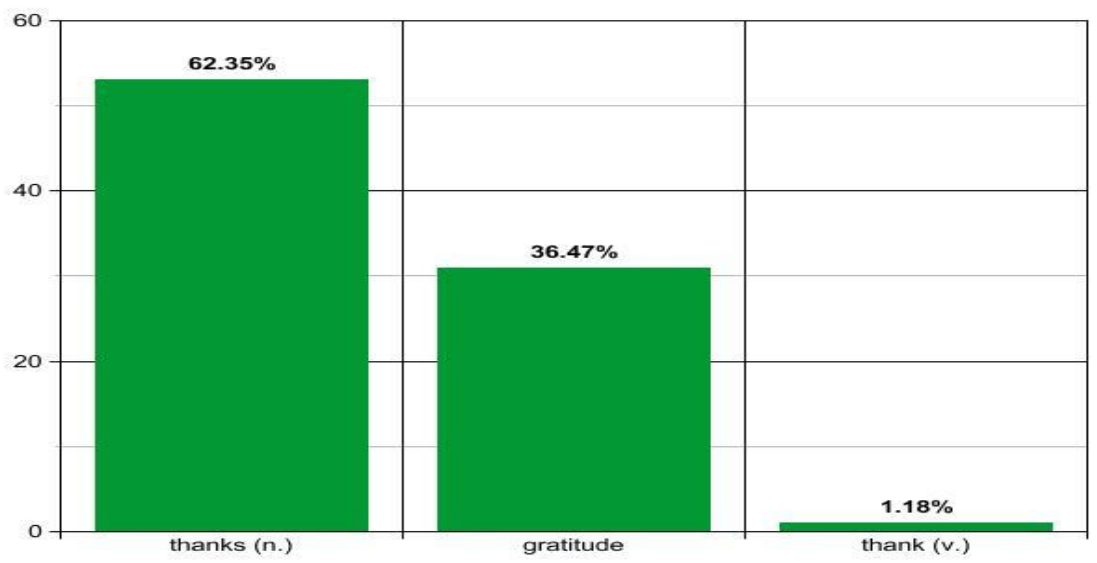

Graph 1. Frequency of use of thanking IFIDs in the Lampeter Corpus of Early Modern English Tracts

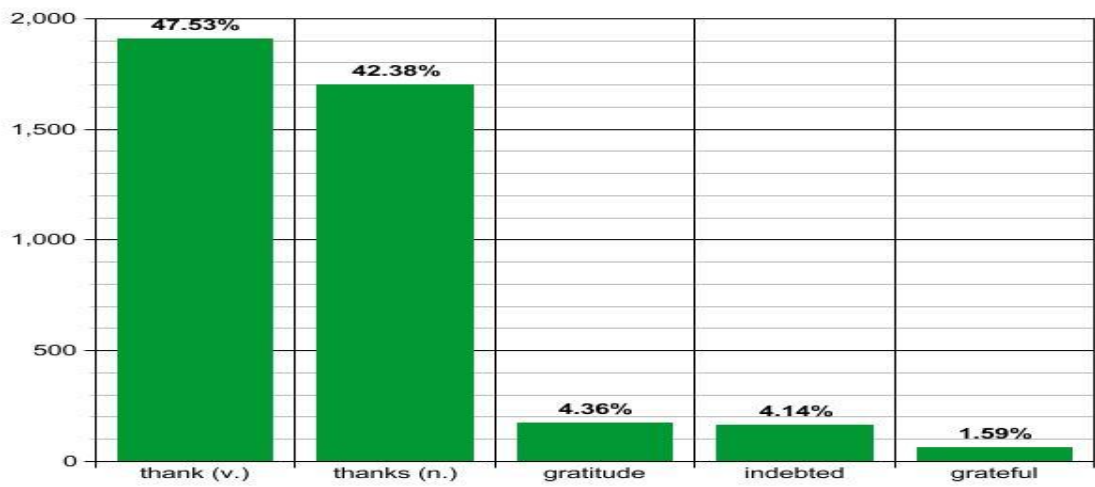

Graph 2. Frequency of use of thanking IFIDs in the Corpus of Late Modern English Texts 


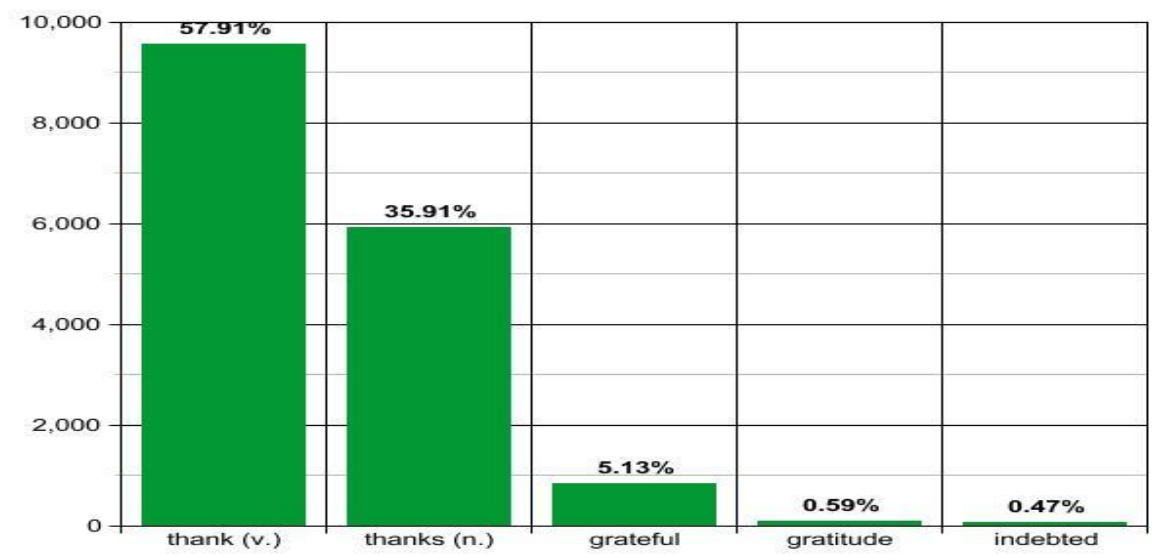

Graph 3. Frequency of use of thanking IFIDs in the British National Corpus

\begin{abstract}
Notes
${ }^{1}$ This is also the case in the Corpus of Late Modern English Texts and the British National Corpus, where the most commonly used IFIDs of thanking are the verb thank, followed by the noun thanks. However, in the Lampeter Corpus of Early Modern English Tracts, there is a minor difference in that the IFID most commonly used is thanks (n.), whereas the IFID thank (v.) is hardly used in the corpus. For more information about the frequency of use of thanking IFIDs in the three electronic corpora, see Graphs 1, 2, and 3 in the Appendix.

${ }^{2}$ Evidence from the electronic corpora supports this claim, because $27.5 \%$ of the speech acts of thanking where the verb thank is used have an explicit performative structure in the Corpus of Late Modern English Texts, as opposed to only $2 \%$ in the British National Corpus.

${ }^{3}$ Because of the relatively small corpus of this study, there is not much evidence to support this claim. However, it has been found that in the Corpus of Late Modern English Texts (CLMET) and the British National Corpus (BNC) when thanks is used in non-elliptical structures, the talk exchange is usually very formal and polite. Examples are:
\end{abstract}

a. But I will at present only add my humble thanks and duty to your honoured mother. (CLMET) 
b. Our thanks are due to the original cast for the creation of these offstage characters. (BNC)

${ }^{4}$ This is not the case in the Lampeter Corpus of Early Modern English Tracts, where the expression gratitude is the second most commonly used IFID of thanking (see Graph 1 in the Appendix), e.g. "[...] no future time shall ever find me wanting in the most inviolable Duty and Gratitude to that merciful Prince who gives me my Life." 5 The electronic corpora also suggest that IFIDs of thanking which express indebtedness are generally disfavored by speakers of EME, LME, and PDE altogether. In the Lampeter Corpus of Early Modern English Tracts, no IFIDs expressing indebtedness are found. In the Corpus of Late Modern English Texts (CLMET) and the British National Corpus (BNC), only few occurrences of the IFID indebted are found (see Appendix ). Examples are:

a. I am indebted to Dr. J.A.H. Murray for this reference, which he kindly supplied from the materials for his great English Dictionary on Historical Principles. (CLMET)

b. I am most indebted to you for your advice, Mr. Stevens. (BNC)

${ }^{6}$ Likewise, in the Lampeter Corpus of Early Modern English Tracts, terms of endearment which intensify the speech act of thanking are hardly found.

${ }^{7}$ Likewise, there are very few occurrences of the adverb humbly the speech acts of the thanking in the Corpus of Late Modern English Texts and none at all in the British National Corpus.

${ }^{8}$ This claim is supported by evidence from the British National Corpus (BNC), where the IFIDs of thanking mainly collocate with the adverb very. Other less commonly used adverbial intensifiers found in the BNC are a lot which collocates with thanks (n.) and extremely, deeply and eternally which collocate with grateful.

${ }^{9}$ Likewise, the use of emphatic $d o$ as an internal intensifier of thanking is very rare in the Corpus of Late Modern English Texts (CLMET) and the British National Corpus (BNC). It should be noted, however, that whenever emphatic do is used to intensify the speech act of thanking, the talk exchange is usually formal, as in: 
a. I assure you I do Thank you for the trouble you have taken about the Neapolitan books, and for the medals that are coming. (CLMET)

b. But I do thank you for your hospitality, sir. (BNC)

${ }^{10}$ Emotional expressions are also rarely found in the speech acts of thanking of the electronic corpora. In the Lampeter Corpus of Early Modern English Tracts, no emotional expressions are found in the speech act of thanking where the IFID thanks (n.) is used. In the Corpus of Late Modern English Texts (CLMET) and British National Corpus (BNC), emotional expressions are found in only $3.5 \%$ and $2 \%$ of the speech acts of thanking where the IFID thank $(v$. $)$ is used. Examples are:

a. Oh, thank you, sir. (CLMET)

b. Oh lovely, thank you. (BNC) 